\title{
Mathematics education in a time of crisis-a viral pandemic
}

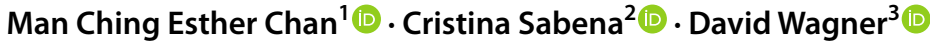

Accepted: 19 September 2021/ Published online: 23 October 2021

(C) The Author(s), under exclusive licence to Springer Nature B.V. 2021

\section{Crisis and change}

"Crisis" is a word that has been used (and possibly abused) a lot in recent years. It may indicate a difficult moment for an individual, a strong feeling of being upset, or a disturbance in a person's existence. Social crises are different. Across the world, the crisis from the COVID-19 pandemic is inescapable. It strongly upsets us, it disturbs our existence, and unites or divides us in different ways.

In the language of economics, especially in classical economics, "crisis" specifically designates a period of economic depression, namely, the phase of a business cycle that is the consequence of generalised overproduction, the basic characteristics of which are a rapid transition from prosperity to depression, a fall in production, widespread unemployment, falling prices, low wages, and falling profits. A well-known example is the general depression of economic activity that began with the Wall Street crash in 1929, which spread to other countries and lasted until the Second World War. Even in the case of the current pandemic, in all countries the emergence of the pandemic has been accompanied by the emergence of an economic crisis. There is a question that has sparked many political discussions and controversies with inextricable ethical implications: Which is more critical in this pandemic era, the health crisis or the economic crisis?

In this time of global crisis due to the COVID-19 pandemic we, our loved ones, and all people suffered tremendous disruptions, pains, and fears. The physical suffering, the isolation, and the compelling demands to care for others in new ways have been real and deep. While we take time to care for each other, ourselves, and others, as scholars it is also our responsibility in a time of crisis to interpret the changing world and develop appropriate research agendas.

We know that crises are not new. Even pandemics are not new. Nevertheless, we are living in a new era. Crisis theorists explain why our crises are becoming more frequent and larger in scale (Topper \& Lagadec, 2013). The world is becoming increasingly interconnected due to advanced technologies for the movement of information, people, and goods. This interconnectivity changes the nature of any potential crisis from a chain

Man Ching Esther Chan

mc.chan@unimelb.edu.au

1 Melbourne Graduate School of Education, The University of Melbourne, Ground floor, 234

Queensberry Street, The University of Melbourne, VIC 3010, Australia

2 Department of Philosophy and Education Sciences, University of Torino, Turin, Italy

3 Faculty of Education, University of New Brunswick, Fredericton, Canada 
of events in a relatively contained ecosystem or society to having global reach. This interconnectivity also accelerates the chains of events. These days, crises can ripple through the globe virtually instantaneously. Stock markets respond immediately as they are globally interdependent. Ideas, concepts, and fears spread as quickly through social media. These ripple effects can impact individual behaviour and community action, from local to national communities.

Thus, crisis theorists have been warning us (humanity) for decades about increasingly large and frequent crises. Such a warning had reached the mathematics education community before: the 2017 Mathematics Education and Society conference's theme was "Mathematics Education and Life at Times of Crisis". Participants in the conference envisioned social crises and the climate crisis. Now we know that these crises connect with the pandemic — see, for example, Ezeibe et al. (2020) on social crises and Banerjee (2020) on the climate crisis in relation to the pandemic. But such warnings extend much further back. We look back to 1973, when Rittel and Webber (1973) theorised problems that are addressed by natural scientists and social planners and coined the concept of a "wicked problem" to describe the problems they were addressing as inescapable highstakes human problems that cannot be clearly defined due to their complex interconnectedness, and that have no clear solution nor method for testing solutions. Steffensen (2017) has pointed to the way climate change presents such problems and identified the importance of such problems to mathematics education. In 1992, Beck developed the concept of "risk society" to theorise the shift in risks humans face from natural disasters to disasters caused by humans. We know that natural risks are increasingly amplified and even caused by human activity (IPCC Working Group 1, 2021).

Topper and Lagadec (2013) drew on Mandelbrot's application of fractal geometry to volatile financial markets to underpin their proposal for how to respond to an increasingly unpredictable world. Using this approach in the current crisis, we see that we have to look through the massive changes and upheaval in the pandemic to examine what lies beneath-the structures that have not changed. When people experience crises, we understandably focus on the significant upheavals that dominate our attention, but Mandelbrot's approach directs us to zoom out and see what we experience as change as representative of something greater and relatively invariant. This approach can help us understand the roots of a crisis. This approach can help us manage the big questions about crises that we face as a field of mathematics education researchers.

Given that we can expect crises more frequently and larger in scale, our research needs to extend beyond this particular crisis to prepare for future crises. That is the goal of this special issue on mathematics education in a time of crisis in this context of a viral pandemic.

To clarify terminology, the virus is called SARS-CoV-2. The disease caused by the virus is called COVID-19. The pandemic is not the virus or the disease alone; it is the social manifestation of the spread of the virus through our interconnected global social systems. The pandemic is both a result of social and environmental realities and a driver of change in these realities. This special issue is focused on the impact of the pandemic on mathematics education in three contexts:

- the teaching and learning of mathematics (in elementary, secondary, and tertiary contexts),

- mathematics education as a research field, and

- mathematics in society. 
We distributed the call for papers for this special issue on April 7, 2020. In the call, we said that authors "may wish to position this particular crisis in the context of other interrelated crises that grip our world, such as, climate change, human migration, the rise of xenophobic nationalism, and growing inequalities". We invited both essays and empirical studies. We received 161 full manuscripts with authors from 36 countries $^{1}$ including sixteen countries in Europe, eight in continental Asia, four in South America, three in North America, three in the Pacific Islands (including Australia and New Zealand), and two in Africa.

From the wealth of strong papers we received, it was difficult to choose which papers to move forward in our process. We expected a single special issue but now have a double issue with 20 papers. Many of the papers that we did not move forward for the special issue have been submitted and published elsewhere. We aimed for a set of papers that represented diverse approaches to the crisis and geographic distribution. In relation to geographic distribution, we were interested in both the location of the authors and the contexts of the research. We knew that the crisis was impacting different regions differently, so we wanted to ensure that the special issue would represent a range of perspectives across contexts.

In this introduction to the special issue, we take an opportunity to reflect on crisis in general and the pandemic in particular from the perspective of mathematics education researchers, informed by the extensive reading and interaction we have engaged in as special issue editors. In our "narrative construction of reality" (Bruner, 1991), we organise our reflections diachronically, adopting a human dimension of time as "time whose significance is given by the meaning assigned to events within its compass" (p. 6). We therefore first reflect on the moment of crisis, which is our present. Then we will see this crisis as an opportunity to look back and find connections from the past, which may nurture our reflection on the present. Finally, we look forward from this crisis to think about future research and action.

\section{The moment of crisis}

At the start of the pandemic at the beginning of 2020, those who followed world news would see similar messages repeat and replicate in different parts of the world. Many countries would first hear about the virus in other countries. Life seemed "normal" until we started to hear about cases emerging in neighbouring regions, countries, and then in our own area. We thought none of this would affect us or our lives until suddenly the government announced that we are in lockdown and people started to make panic purchases that left supermarket shelves empty of daily essentials. Face masks and hand sanitisers became essential items in many countries. We had to navigate and learn the new restriction rules that government officials announced and implemented overnight. Universities and schools made announcements about switching to online teaching or remote learning, and suddenly everyone had to learn to use new online platforms. There was a lot of resistance, frustration, and uncertainty among teachers, students, and parents (Matthews et al., 2021 , in this special issue). Online education resources that had been neglected by many

\footnotetext{
1 We recognise that any count of countries and regions is problematic because there are disputed boundaries.
} 
for years became the essential teaching and learning guide (Borba et al., 2010; Salmon, 2011). Educators had to quickly learn how to teach and engage students in an online environment (Albano et al., 2021, in this special issue). Activities that were designed to be carried out face-to-face had to be re-designed using breakout rooms, digital whiteboards, or screenshare.

Many researchers had to pause their research projects as schools shut down and the classroom environment drastically changed due to the pandemic. At the same time, some would see this as a unique opportunity to understand how human society was responding to challenges in a crisis, but our research activities were also being challenged because of the crisis. Should our responsibility be to document, describe, or explain this crisis (see, e.g., Little, 1991)? Or should we try to theorise or predict how this crisis is going to play out and end? How do we balance our ethical responsibility to not put a burden on our participants when they are experiencing high levels of stress and uncertainty but still fulfil our research roles? Many researchers had to navigate and negotiate these questions with ourselves, our colleagues, and our participants when deciding on whether to pursue research during this time.

As time went on, people started to adjust to the "new normal". Lockdowns became a repeat occurrence in different places. While initially the international community were being physically separated due to travel restrictions, our life appeared to be more closely connected by this pandemic as we realised that we shared many similar experiences in our local context. Online meetings and conferences became commonplace. People started to play around with online backgrounds and filters to decorate our monotonous work-fromhome life. In between lockdowns, some started to say that they enjoyed working from home, not having to commute to workplaces.

\subsection{Questions about this special issue}

As we, the special issue editors, started to read queries from scholars interested in contributing to this special issue, we could see that the crisis had made it difficult in different parts of the world to carry out empirical research in schools and with families. Some researchers resorted to investigating their own teaching practice and their own response to the crisis (e.g., Krause et al., 2021; Maciejewski, 2021; both in this special issue). Others turned to media and textual analysis and showed fascinating and critical demands on statistical literacy and visual representation during this pandemic (e.g., Rubel et al., 2021; Sousa Silva et al., 2021; both in this special issue). The mathematics curriculum was under scrutiny in terms of preparing citizens to respond to the pandemic (e.g., Zavaleta, 2021, in this special issue). Government response to the crisis also became a telling lens in revealing how citizens trust or distrust authority in a time of crisis (e.g., Allen \& Trinick, 2021; in this special issue).

With the vast number of manuscripts submitted to this special issue, the review process was also being challenged. Many potential reviewers found it difficult to commit to reviewing papers. For those who responded, a few raised the question of whether it could be too early to start reflecting on the crisis situation, queried the contribution of papers that focused on documenting the crisis, or raised concerns about prospective non-empirical papers.

Some colleagues raised the concern that those who managed to submit a paper to the special issue were privileged individuals who had time to write at a time of crisis. They noted historic gender inequities in who would take on the sudden demands in home care 
of children (Flaherty, 2020; Vomvoridi-Ivanovic \& Ward, 2021) and noted the advantages that wealth, and access to research and secure health services confer to the few. We sympathised with these questions and weighed the benefits of research responding to one of the most significant events in education against the worries about the first voices in this research being dominated by voices of privileged demographics. We looked at the authors of the submitted papers by gender and found women barely outnumbered men based on our experiences with gendered names. ${ }^{2}$ We considered the regions from which we received papers and found more diverse representation than historical representation as identified by Mesa and Wagner (2019). In our selection of which papers to invite to move forward in the process, we aimed for representation from diverse regions, considering both the region of the author and the region focused on in the research. Because we received so many strong papers, more than we could accommodate in the special issue, we turned away some papers on the basis of regional representation, and encouraged the authors to submit their work as regular papers in Educational Studies in Mathematics or in other venues. We similarly turned away papers that were not sufficiently focused on the pandemic or did not deal with aspects of it specific to mathematics education.

A related question that emerged in discussing this special issue is this: When is the appropriate time to do research on an emergent phenomenon? We see that there is value in documenting what is going on with the pandemic situation in various contexts. The documentation will certainly allow for more informed reflection on the era in future scholarship. Additionally, the scholarship already prompts reflection. Indeed, all the papers in this special issue have an element of reflection in them. The prompt to share reflections and practices when we are still facing a terrible problem is not only a challenge, but it is also a way to act as a community, to keep us socially close, in a time when we are prevented from meeting physically. Possibly, this also explains the reason why the special issue call received so many papers, even in such a short time. Krause et al. (2021, in this special issue) witnessed a tension between a certain "situatedness" of the current reality and the "generality" (what goes beyond the pandemic situation). The relatively short deadlines we asked for in the call for papers enabled authors to seize fully the situatedness, in a sense contributing to it. On the other hand, we asked for contributions that were able to go beyond the current situation, towards a more general view of crisis. Skovsmose's (2021, in this special issue) paper took on that challenge directly.

\subsection{Responsibilities of mathematics educators in crisis}

What are our responsibilities as mathematics educators in such a time of crisis? We recognise that this is a difficult question because of the many competing demands we face. A mathematics educator in a time of big or small crisis would face local, immediate challenges. At the same time, there is also the possibility to step back to ask big questions. Many would find it important to devote time to love the people in their families and communities at a time of crisis. Whether we are mathematics teachers or teacher educators, we would find it important in our teaching roles to help our students achieve their immediate needs, even if those needs relate to problematic systems. For example, students may have a "need" to learn how to prove trigonometric identities in order to pass a course and qualify for a biology programme that sets

\footnotetext{
${ }^{2}$ We were aware that this measure may have resulted in misclassification because some names were unfamiliar to us.
} 
them up for their career goal. Even if we doubt the value of trigonometric identities in school curriculum (and perhaps especially in a pandemic) or question the focus on these identities for biologists, we may feel obliged to think that it is still important to support the student's success in the systems that are currently in force. In our research, we may find it important to study the local, immediate needs but also look at the big questions and examine the structure beneath the crisis. What is invariant? And where that structure is unjust, how can it be changed? And it could be equally important to reflect on how all these different levels of action speak to each other: family/community, students, practice-level research, system-level research.

In the papers we received for this special issue, we saw scholars looking for accessible data that would help the field understand the pandemic. This was not easy. The pandemic makes it hard to start new studies involving participants. And we know that studies of social structures really need researchers to listen to the people most impacted by the structures. Over time, we expect that we will see more research that uses data that are harder to access, with deep engagement with the people most impacted by the crises.

We know some mathematics teachers and mathematics teacher educators who have seen the pandemic as a prompt to re-examine their teaching (e.g., Brunetto et al., 2021, and, in this special issue Albano et al., 2021; Gosztonyi, 2021; Maciejewski, 2021). One may wonder how students would accept a focus on the usual skills and knowledge when they are bombarded daily with media coverage and government releases about the pandemic situation. One should expect that this supposedly powerful mathematics would be used in class to address the most obvious disruption of our era. We would expect a call from students and from society, echoing the decades of injunction from Ubiritan D'Ambrosio (1994, 2007, 2015) and others (e.g., Mendick, 2017), to examine the complicity of mathematics in the structures that allowed the virus to thrive, in addition to the possibilities for using mathematics for justice in these times. However, speaking from our own experiences, we see students, teachers, families, and politicians focused on the compelling, immediate, local needs. Many are distracted from asking the deep questions, distracted by our social systems and the immediate needs of disrupted networks.

One thing that is immediately clear in pandemic teaching is the inequities, including:

- unequal access to internet

- unequal access to computers and tablets

- unequal availability of space at home for uninterrupted time

- unequal competing demands for time.

Even while teachers and school systems work very hard at combatting them, these inequities persist. Again, this is another example of something that is invariant in this time of massive change. For example, we have research that shows inequities persisting through the pandemic: rural families in Turkey have greater challenges than others (Y1lmaz et al., 2021, in this special issue), the needs of Indigenous students are ignored (Allen \& Trinick, 2021, in this special issue), students of colour are marginalised (Matthews et al., 2021, in this special issue), and students who have recently migrated are ignored. The effects of poverty are magnified.

\section{Crisis as an opportunity to look back}

For many of us, the pandemic situation appeared as a totally new phenomenon, in front of which we felt completely unprepared. But looking at human history, we may indeed recognise that this phenomenon is not new, rather a sort of periodic feature. We have to 
recognise also that the memory of previous pandemics is not felt in the same way in the world: it is indeed stronger, and still felt as a trauma, for many Indigenous marginalised groups around the world-for example, that of Māori in New Zealand as documented by Allen and Trinick (2021, in this special issue).

On the other hand, referring to past epidemics may be a way to gain tools for reflection on the present, without feeling the psychological pressure that such a critical situation may place on us. This is the choice made by Gosztonyi (2021, in this special issue) in her experience with a group of secondary teachers deepening the scientific debate arisen in the XVIII century between Bernoulli and d'Alembert about the smallpox epidemic and the risks and advantages of inoculation (a primitive antecedent of vaccination). In her perspective, historical texts are proposed as transitional objects in the interaction with teachers, indirectly stimulating discussions about the problems with which they are concerned.

The past may emerge in our reflection also in sharp contrast with the present. In one of the outcomes of the pandemic crisis, schools closed and teachers had to face a sudden, unexpected change from face-to-face to distance teaching: Albano et al. (2021, in this special issue) report the subjective point of view of Italian teachers by means of logbooks and show that two temporal periods may be identified, namely, the period of bewilderment and the period for reflection and elaboration. Such a reflection/elaboration is prompted by the current situation through a contrast with the past situation. This contrast reveals key elements of the teaching-learning system in which teachers were embedded before the disturbance. Imagining and advocating totally or partially different educational/school settingspossible worlds in Bruner's words (1986), as Albano et al. pointed out—realises an implied critique of the existing/past world. But the pandemic experience has taught us that the past world rapidly evolved into the existing world, which is, in turn, rapidly evolving into a past world. This evolution leaves us with a minimal sense of what is indeed the actual world and with unstable visions for the future.

A historicized approach is also helpful to understand the present. Ziols and Kirchgasler (2021, in this special issue) explored how distinctions of health and pathology have been dynamically interwoven with mathematics education for two centuries. In this way, they open a dialogue about implications of these historical traces for issues of injustice today. This kind of vision aligns with Mandelbrot's approach to addressing crisis: to look through or past the shocking disruptions to identify what is invariant (Topper \& Lagadec, 2013).

Adopting a Bourdieusian approach, Allen and Trinick (2021, in this special issue) framed the difference between Māori and English-language schools' capacity to maintain continuity of mathematics instruction while schools were closed due to the COVID-19 pandemic, as linked to the limited bank of digital mathematics resources in the Māori language. They interpreted this disparity as the outcome of socially determined differences in cultural capital, which are heritages of the pre-pandemic past.

Borba (2021) saw the pandemic as a prompt to reflect on mathematics education as a research field, particularly in the growing awareness of the way humans and their media depend on each other for mathematics learning and teaching. Others in the special issue suggested a new research agenda in their discussions. We identify an important opportunity and need to reflect on the field in the ways identified above, to understand the past and present manifestations of research in the field.

We note that the tremendous response to this special issue demonstrates the resiliency of the field and showcased many well-developed research methodologies and collaboration networks. We find the results of the survey done by Bakker et al. (2021) to be of interest. Just before the pandemic struck, they surveyed mathematics educators around the world 
to ask what themes research in mathematics education should focus on in the coming decade. They asked respondents a year later (in November 2020) if the pandemic changed their views on the themes. Nine of their respondents identified no changes in their views, eight identified clearly different views, and 45 saw the importance of their initial themes reinforced. One way to see these results is as evidence that the field already understood the important issues that the pandemic revealed. However, we should be careful about this conclusion because we know for ourselves that we use the tools we already know to interpret new phenomena. While we see authors in this special issue using theories and methodologies that fit their previous research approaches, we also see changes. Many researchers are becoming increasingly interested in and aware of the work in our field on online teaching media: for this special issue we received many manuscripts from authors studying the move to online teaching who, as far as we know, have not addressed this teaching medium before. Nevertheless, the fact that the field has people specialised in online teaching research (e.g., Borba et al., 2010), for example, for the past thirty years with relatively few people needing to refer to until now, shows that something is working in, shall we say, the ecology of the educational research field that allows us to be responsive to a diverse range of situations.

\section{Crisis as an opportunity to look forward}

Crises also prompt us to look forward to projected and potential futures. The Secretary General of the United Nations, in his July 2020 lecture (the Nelson Mandela Lecture), noted that "The pandemic has demonstrated the fragility of our world. It has laid bare risks we have ignored for decades: inadequate health systems; gaps in social protection; structural inequalities; environmental degradation; the climate crisis" (Guterres, 2020). He added that "The virus poses the greatest risk to the most vulnerable: those living in poverty, older people, and people with disabilities and pre-existing conditions." He concluded that "COVID-19 is a human tragedy. But it has also created a generational opportunity. An opportunity to build back a more equal and sustainable world." Others have made similar observations. For example, novelist Arundahti Roy (2020) has documented the pandemic in India and concluded:

Historically, pandemics have forced humans to break with the past and imagine their world anew. This one is no different. It is a portal, a gateway between one world and the next. We can choose to walk through it, dragging the carcasses of our prejudice and hatred, our avarice, our data banks and dead ideas, our dead rivers and smoky skies behind us. Or we can walk through lightly, with little luggage, ready to imagine another world. And ready to fight for it.

People who experienced the world before the pandemic as treacherous and broken may wish for a transformed world. As researchers, many of us may have had relatively satisfying experiences before the pandemic, and thus may not wish for world transformation. We should take a moment of crisis as a time to carefully imagine the future.

We should ask, what warrants change and what should be maintained? These questions should be applied both to mathematics teaching practices and to research approaches. And we should inform our considerations with careful attention to the perspectives of a wide range of stakeholders in mathematics education—students, teachers, and others, all from a 
wide cross section of contexts. The question boils down to a moral question: whose needs should be foregrounded? This question and other related questions were addressed by Adler and Lerman (2003). We suggest that the pandemic compels new consideration of the ethics of research in mathematics education.

\subsection{New visions for mathematics teaching}

When we look forward as researchers, we should question both curriculum and pedagogies. The question of curriculum is widely discussed in this special issue (Kollosche \& Meyerhöfer, 2021; Rotem \& Ayalon, 2021; Sánchez Aguilar and Castañeda, 2021; Sousa Silva, et al., 2021; Zavaleta, 2021, all in this special issue). It is indeed helpful to look at the mathematics that has appeared publicly in the pandemic to inform the mathematics that should be taught because citizens should be equipped to understand the mathematics they will experience in the world. Kwon et al., (2021, in this special issue) investigated the use of graphs in Korea's news media during the COVID-19 outbreak, providing implications for future teaching and learning of graph literacy in school mathematics courses. Heyd-Metzuyanim et al. (2021, in this special issue), after examining the Israeli public's understanding of mathematical notions that are required for understanding the pandemic and predicting its spread, demonstrate that mathematical identity may significantly hinder adults' engagement with such information. Kollosche and Meyerhöfer (2021, in this special issue) took a more critical stance and referred to different discussions in German mass media on the pandemic policy in the SARS-CoV-2 crisis in 2020 to argue that the critical evaluation of experts' use of mathematics by laypersons is not possible in all relevant cases, and discuss possible implications of this result.

We note that when people develop media to inform the public, they make their decisions about what mathematics to use and how to represent it based on the mathematics they expect the public to understand. Thus, we see a circularity: curriculum would be designed on the basis of the mathematics that people are applying in their lives, and such mathematics is influenced by the mathematics learned at school, hence influenced or even determined by the curriculum itself. A time of crisis may help disturb such circularity, identifying the mathematics that are needed in curriculum.

With this new vision, mathematics educators and mathematicians will need to identify mathematics that would be needed for interpreting crises so that this mathematics could inform the public. In addition to the widely circulated mathematics, there is important mathematics being done to address significant needs during the pandemic. Some of this mathematics may be part of the answer to the above question: what mathematics should be taught? Maciejewski (2021, in this special issue) contributed an account of his struggle with this question and reported on his approaches to developing prospective mathematics teachers' understanding of exponential growth, and connectivity. Also, this question has been discussed less formally, for example, in the closing plenary panel of the International Congress on Mathematical Education in 2021, panellists answered this question. The question of how to address this mathematics requires much more thought. And more research, we suggest. Even so, the question of what mathematics should be taught surely needs attention given the new realities exposed by the pandemic. The basic question underlying any evaluation of mathematics curriculum is this: What should every citizen know? Surely the answer is different than it was thirty years ago, considering the massive changes in interconnectivity in our world and the related growth of planet-wide crises. To answer this question, we need to identify the human and social problems of our time. Here we 
identify some questions that ask about the root factors in this pandemic; we know there are other questions like these:

- What mathematics is necessary to understand interconnectivity?

- What mathematics is needed to understand climate?

- What mathematics is needed to understand biodiversity?

- What mathematics is needed to understand wealth distribution?

It is not enough to identify pressing problems. They need to be prioritised. The pandemic pushes us to change priorities because we see how fragile societies are. Nevertheless, priority-setting remains an important function. Underneath the question of priority-setting, we will find assumptions about whose interests are most important. There are others who can help us answer these moral questions, but as researchers we have to make these determinations ourselves as we make decisions about where to devote our own resources in research. We can do our own evaluations of priorities, or we can make decisions about whose guidance we follow in such priority-setting.

Again, as it becomes clear in Maciejewski's (2021, in this special issue) account of teaching mathematics relevant to the pandemic, we see the importance of questions about how it should be taught. Questions of how to teach mathematics are also now impacted with the field's new understanding of different media for teaching mathematics. Some of the studies in this special issue address the sudden disruptions in teaching media (Albano et al., 2021; Borba, 2021; both in this special issue), but the studies also identify mathematics teachers' learning about their teaching and how to use new media. Drijvers et al., (2021, in this special issue) found that teachers in Flanders, Germany, and the Netherlands reported a remarkable increase in their confidence in using digital technologies during the lockdown. We expect that this learning will be applied to emergent practices post-pandemic. Some early results concerning the online education tool of the "micro-classes" in China are given by Xie et al. (2021, in this special issue).

As we reflect on the responsibilities of mathematics educators within the pandemic, we see that the same questions apply to future research. We are reminded that crisis is not new, and thus, we can look to pre-pandemic scholarship for some guidance on future research agenda in relation to crisis. In particular we point to Vithal and Valero's (2003) consideration of mathematics education research in social and political crisis and to a symposium convened by Parra et al. (2017) which prompted conversation about whose perspectives should be foregrounded in research in crisis contexts.

\subsection{Reflection on the role of mathematics}

Finally, we see that the role of mathematics is itself part of the crisis. Mathematics has underpinned technologies that have pushed species into new patterns of behaviour and that have made the world more connected. Thus, mathematics is underneath the emergence of the coronavirus that drove this pandemic and underneath the social systems that paved the way for its rapid spread. Ubiritan D'Ambrosio implored mathematics educators for decades to examine the role of mathematics in shaping the world (e.g., D'Ambrosio, 1994) and to advocate for such examination in school mathematics (e.g., D'Ambrosio, 2007, 2015). Meanwhile, the way mathematics has been taught has influenced how people have understood the crisis and thus affected their actions within the crisis, again contributing to the particular rates of spread. For example, mathematics education practices have impacted the 
ability and willingness of citizens to read and trust statistics and modelling, which impacts both their decisions in the pandemic and the rise of certain political voices. As our field grapples with the new world, we are compelled to consider our complicity in the problems we see before us. Nevertheless, this critical reflection should not undermine our confidence that mathematics and good mathematics teaching can make important contributions to society. Rather, we need to be sure to include self-examination in our visions for the future.

\section{A final word}

Etymologically, the term crisis comes from the Greek krisis, which refers to choice, decisions, and decisive phases of an illness. It relates to the word krino, which means to distinguish. If we look at the etymology, it is always a time of crisis, because we are always being called upon to choose among different alternatives; even doing nothing to change a situation is an alternative and a choice. Taking different perspectives and addressing the most dynamic sense of the crisis, the authors of this special issue proactively seized the chance to write in the momentum of the pandemic crisis to offer alternatives to the mathematics education field. In such a perspective, it is our wish that the papers in this special issue will constitute a little light for future generations.

\section{References}

Adler, J., \& Lerman, S. (2003). Getting the description right and making it count: Ethical practice in mathematics education research. In A. Bishop, M. Clements, C. Keitel-Kreidt, J. Kilpatrick, \& F. Leung (Eds.), Second international handbook of mathematics education (pp. 441-470). Springer.

Albano, G., Antonini, S., Coppola, C., Dello Iacono, U., \& Pierri, A. (2021). 'Tell me about': A logbook of teachers' changes from face-to-face to distance mathematics education. Educational Studies in Mathematics. https://doi.org/10.1007/s10649-021-10108-2

Allen, P., \& Trinick, T. (2021). Agency-structure dynamics in an indigenous mathematics education community in times of an existential crisis in education, health, and the economy. Educational Studies in Mathematics. https://doi.org/10.1007/s10649-021-10098-1

Bakker, A., Cai, J., \& Zenger, L. (2021). Future themes of mathematics education research: An international survey before and during the pandemic. Educational Studies in Mathematics, 107(1), 1-24.

Banerjee, N. (2020). COVID-19, public health, and climate change: Q\&A with Aaron Bernstein. Global Observatory, March 20, 2020. https://theglobalobservatory.org/2020/03/covid-19-public-health-clima te-change-qa-with-aaron-bernstein/. Accessed 28 Sep 2021.

Beck, U. (1992). Risk society: Towards a new modernity. Sage Publications.

Borba, M. (2021). The future of mathematics education since COVID-19: Humans-with-media or humans-with-non-living-things. Educational Studies in Mathematics. https://doi.org/10.1007/ s10649-021-10043-2

Borba, M. C., Malheiros, A. P. d. S., \& Zulatto, R. B. A. (Eds.). (2010). Online distance education. Sense Publishers.

Bruner, J. (1991). The narrative construction of reality. Critical Inquiry, 18(1), 1-21.

Brunetto, D., Bernardi, G., Andrà, C., \& Liljedahl, P. (2021). Teaching as a system: COVID-19 as a lens into teacher change. Educational Studies in Mathematics. https://doi.org/10.1007/s10649-021-10107-3

D'Ambrosio, U. (1994). Cultural framing of mathematics teaching and learning. In R. Biehler, R. Scholz, R. Sträßer, \& B. Winkelman (Eds.), Didactics of mathematics as a scientific discipline (pp. 443-455). Kluwer.

D'Ambrosio, U. (2007). The role of mathematics in educational systems. ZDM - Mathematics Education, 39(1-2), 173-181. 
D'Ambrosio, U. (2015). From mathematics education and society to mathematics education and a sustainable civilization. Proceedings of the eighth international mathematics education and society conference (vol. 1, pp. 19-30). Portland, Oregon, USA.

Drijvers, P., Thurm, D., Vandervieren, E., Klinger, M., Moons, F., van der Ree, H., Mol, A., Barzel, B., \& Doorman, M. (2021). Distance mathematics teaching in Flanders, Germany, and the Netherlands during COVID-19 lockdown. Educational Studies in Mathematics. https://doi.org/10.1007/ s10649-021-10094-5

Ezeibe, C., Ilo, C., Ezeibe, E., Oguonu, C., Nwankwo, N., Ajaero, C., \& Osadebe, N. (2020). Political distrust and the spread of COVID-19 in Nigeria. Global Public Health, 15(12), 1753-1766.

Flaherty, C. (2020, April 21). No room of one's own: Early journal submission data suggest COVID-19 is tanking women's research productivity. Inside Higher Ed. https://www.insidehighered.com/news/ 2020/04/21/early-journal-submission-data-suggest-covid-19-tanking-womens-research-productivi ty. Accessed 8 Sep 2021.

Gosztonyi, K. (2021). How history of mathematics can help to face a crisis situation: The case of the polemic between Bernoulli and d'Alembert about the smallpox epidemic. Educational Studies in Mathematics. https://doi.org/10.1007/s10649-021-10077-6

Guterres, A. (2020). Secretary-General's Nelson Mandela lecture: "Tackling the inequality pandemic: A new social contract for a new era". https://www.un.org/sg/en/content/sg/statement/2020-07-18/ secretary-generals-nelson-mandela-lecture-\%E2\% 80\% 9 Ctackling-the-inequality-pandemic-newsocial-contract-for-new-era\%E2\%80\%9D-delivered. Accessed 8 Sep 2021.

Heyd-Metzuyanim, E., Sharon, A., \& Baram-Tsabari, A. (2021). Mathematical media literacy in the COVID-19 pandemic and its relation to school mathematics education. Educational Studies in Mathematics. https://doi.org/10.1007/s10649-021-10075-8

IPCC Working Group 1. (2021). Climate change 2021: The physical science basis [Assessment Rep No. 6]. https://www.ipcc.ch/report/ar6/wg1/. Accessed 8 Sep 2021.

Kollosche, D., \& Meyerhöfer, W. (2021). COVID-19, mathematics education, and the evaluation of expert knowledge. Educational Studies in Mathematics. https://doi.org/10.1007/ s10649-021-10097-2

Krause, C., Di Martino, P., \& Moschkovich, J. (2021). Tales from three countries: Reflections during COVID-19 for mathematical education in the future. Educational Studies in Mathematics. https:// doi.org/10.1007/s10649-021-10066-9

Kwon, O., Han, C. Lee, C., Lee, K., Kim, K., Jo, G., \& Yoon, G. (2021). Graphs in the COVID-19 news: A mathematics audit of newspapers in Korea. Educational Studies in Mathematics. https://doi.org/ 10.1007/s10649-021-10029-0

Little, D. (1991). Varieties of social explanation: An introduction to the philosophy of social science. Westview.

Maciejewski, W. (2021). Teaching math in real time. Educational Studies in Mathematics. https://doi. org/10.1007/s10649-021-10090-9

Matthews, L., Jessup, N., \& Sears, R. (2021). Pandemic shifts: Power and reimagined possibilities in mathematics learning for Black communities. Educational Studies in Mathematics. https://doi.org/ 10.1007/s10649-021-10106-4

Mendick, H. (2017). Mathematical futures: Discourses of mathematics in fictions of the post-2008 financial crisis. Proceedings of the ninth international mathematics education and society conference, (vol. 1, pp. 74-89), Volos, Greece.

Mesa, V., \& Wagner, D. (2019). Behind the door: A critical look at the process of publication in Educational Studies in Mathematics. Educational Studies in Mathematics, 101(3), 301-324.

Parra, A., Bose, A., Alshwaikh, J., González, M., Marcone, R., \& D’Souza, R. (2017). "Crisis" and interface with mathematics education research and practice: An everyday issue. In A. Chronaki (Ed.), Proceedings of the Ninth International Mathematics Education and Society Conference, Volos, Greece (Vol. 1, pp. 174-178).

Rittel, H., \& Webber, M. (1973). Dilemmas in a general theory of planning. Policy Sciences, 4(2), $155-169$.

Rotem, S., \& Ayalon, M. (2021). Exploring Israeli high school graduates' explanations for the spread of the coronavirus. Educational Studies in Mathematics. https://doi.org/10.1007/s10649-021-10042-3

Roy, A. (2020). The pandemic is a portal. Financial Times, April 3, 2020. https://www.ft.com/content/ 10d8f5e8-74eb-11ea-95fe-fcd274e920ca. Accessed 8 Sep 2021.

Rubel, L., Nicol, C., \& Chronaki, A. (2021). Critical mathematics reading of data visualizations: Reimagining through reformatting, reframing, and renarrating. Educational Studies in Mathematics. https://doi.org/10.1007/s10649-021-10087-4

Salmon, G. (2011). E-moderating: The key to teaching and learning online (3rd ed.). Routledge. 
Sánchez Aguilar, M., \& Castañeda, A. (2021). What mathematical competencies does a citizen need to interpret Mexico's official information about the COVID-19 pandemic? Educational Studies in Mathematics. https://doi.org/10.1007/s10649-021-10082-9

Sousa Silva, A., Serrano Barbosa, M., de Souza Velasque, L., da Silveira Barroso Alves, D., \& Nascimento Magalhães, M. (2021). The COVID-19 epidemic in Brazil: How statistical education may contribute to unravel the reality behind the charts. Educational Studies in Mathematics. https://doi. org/10.1007/s10649-021-10112-6

Skovsmose, O. (2021). Mathematics and crises. Educational Studies in Mathematics. https://doi.org/10. 1007/s10649-021-10037-0

Steffensen, L. (2017). Critical mathematics education and post-normal science: A literature overview. Philosophy of Mathematics Education Journal, 32. https://socialsciences.exeter.ac.uk/education/research/ centres/stem/publications/pmej/pome32/index.html. Accessed 8 Sep 2021.

Topper, B., \& Lagadec, P. (2013). Fractal crises-A new path for crisis theory and management. Journal of Contingencies and Crisis Management, 21(1), 4-16.

Vithal, R., \& Valero, P. (2003). Researching mathematics education in situations of social and political conflict. In A. Bishop, M. Clements, C. Keitel-Kreidt, J. Kilpatrick, \& F. Leung (Eds.), The second international handbook of mathematics education (pp. 545-591). Springer.

Vomvoridi-Ivanovic, E., \& Ward, J. (2021). Academic motherhood in mathematics teacher education during COVID-19: Breaking the silence and shifting the discourse. REDIMAT-Journal of Research in Mathematics Education, 10(1), 41-61.

Xie, Z., Xiao, L., Hou, M., Liu, X., \& Liu, J. (2021). Micro classes as a primary school-level mathematics education response to COVID-19 pandemic in China: Students' approval degree and perceived equity. Educational Studies in Mathematics. https://doi.org/10.1007/s10649-021-10111-7

Yılmaz, A., Gülbağcı Dede, H., Sears, R., \& Yıldız Nielsen, S. (2021). Are we all in this together? Mathematics teachers' perspectives on equity in remote instruction during a pandemic. Educational Studies in Mathematics. https://doi.org/10.1007/s10649-021-10060-1

Zavaleta, L. (2021). Emergent curriculum in basic education for the new normality in Perú: Orientations proposed from mathematics education. Educational Studies in Mathematics. https://doi.org/10.1007/ s10649-021-10100-w

Ziols, R., \& Kirchgasler, K. (2021). Health and pathology: A brief history of the biopolitics of US mathematics education. Educational Studies in Mathematics. https://doi.org/10.1007/s10649-021-10110-8

Publisher's note Springer Nature remains neutral with regard to jurisdictional claims in published maps and institutional affiliations. 